\title{
INDEX (Vol. 64, No. 1-6, 2021)
}

\section{FULL ARTICLES}

No. Page

Qingfei Xu and Xinyu YANG: Performance Evaluation on Packet Transmission for Distributed Real-time Avionics Networks Using Forward End-to-End Delay Analysis.

Takeshi KANDA, Shunsuke KiKUCHI, and Honoka KinO: Experimental Validation of Off-design Combustion for

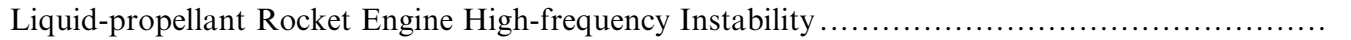

Koji Fujtta, Kakeru Kurane, Koichi TaKahashi, and Hiroki Nagai: Effects of Propeller Position and Rotation Direction on the Ishii Wing at a Low Reynolds Number.

Yoya Gon and Nozomu Kogiso: Effect of Member Length Uncertainty and Backlash on Deformation Accuracy for a High-Precision Space Truss Structure

Suiyuan SHEN, Qinghua ZHU, and Jinfa XU: Research on the Influence of Key Parameters on the Aerodynamic Characteristics of Shaftless Ducted Rotors

Shuai Guo, Jin ZHANG, and Yazhong LuO: Simulation and Evaluation of a Space Station Operational Plan Considering Launch Delay of Cargo Vehicles

Daichi Haraguchi, Shota Isakari, Yasuyuki Yano, and Akira KaKami: Performance Evaluation of Combustioncontrollable 0.1-N-Class Solid Propellant Microthrusters Using Laser Heating ......................

Takuya Arakawa, Kiyoshi NoJima, Kan Kobayashi, and Sadatake TomioKa: Fuel/Air Mixing in Reacting and Nonreacting Flows within a Dual-mode Combustor .

Yuhei KIKUYA, Yohei IwASAKI, Yoichi Yatsu, and Saburo MatunAGa: Attitude Determination Algorithm Using Earth Sensor Images and Image Recognition

Dae Hwan KIM, Suji LeE, and Youngbin Yoon: Droplet Size Control in Gas-Liquid Pintle Injectors.....

Ryo Suzumoto, Satoshi IKari, Norihide MiYamura, and Shinichi NAKASUKA: $\mu$ m-class Control of Relative Position and Attitude for a Formation Flying Synthetic Aperture Telescope with Micro-satellites ............

Yunxiang CuI, De Yan, Zhiqiang Wan, Yaokun Wang, Xiaochi Zhang, Qiyue Guo, Hao Teng, Yaoguo LiU, and Menglin YANG: Design and Realization of New Conceptual Collectible Rotor for Compound Aircraft ......

Carmen Pardini, Luciano Anselmo, David M. LuCchesi, Roberto Peron, Massimo Bassan, Carmelo Magnafico, Giuseppe PUCACCO, and Massimo VISCO: Sounding the Atmospheric Density at the Altitude of LARES and Ajisai during Solar Cycle 24

Takahiro SASAKI, Yu NAKAJIMA, and Toru YAmamoto: Proximity Approaches and Design Strategies for NonCooperative Rendezvous. V-bar Hopping vs. Spiral Approach

Masato OKAмото, Shota FUKATSU, and Daisuke SASAKI: Measurement of Unsteady Aerodynamic Characteristics of a Heaving Wing in a Low Reynolds Number Flow ............................................

Masayuki ANYoJI, Daiju Numata, Hiroki NAgAI, and Keisuke ASAI: Supersonic Ejector-Driving System under Low Pressure: A Performance Evaluation.

Ryota MoRI: Safety Analysis of Reduced Route Spacing for RNP 2 under Radar Environment .....

Jin Wu, Chengxi Zhang, and Ming LIU: Hybrid Geomagnetic Attitude and Orbit Estimation Using Time-Differential Feedback

Qiang Zhang, Fumiya TAKAHAshi, Kotaro SAto, Wakana Tsuru, and Kazuhiko Yokota: Jet Direction Control Using Circular Cylinder with Tangential Blowing....

Takayuki IsHIDA, Masaki TAKAHASHI, and Seisuke FuKUDA: Crater Detection Robust to Illumination and Shape Changes using Convolutional Neural Network

Ziwen LI, Xiangyuan ZENG, and Shuquan WANG: Hopping Trajectory Planning for Asteroid Surface Exploration Accounting for Terrain Roughness

Atsushi FUJIMORI and Shinsuke OH-HARA: An Effective Maximal-Length Sequence Design for System Identification of a Continuous-Time Linear Aircraft Model

Mariko AkiYama, Keita Nishi, Yoshihito Mannami, Masaya Murohara, Hiroyuki KoIzUmi, and Kimiya KomurasaKi: Feasibility Study of a Hybrid Thruster using Wire-Shaped Magnesium and Water for Application to Small Spacecraft

Mengying Zhang, Qin XU, and Qingbin ZHANG: Launch Vehicle Classification for Decision-Making of Small Satellite Launch Options.

Zhaihe ZHOU, Yulu ZHONG, Chuanwei ZENG, and Xiangrui TIAN: Attitude Estimation Using Parallel Quaternion Particle Filter Based on New Quaternion Distribution.

Masashi Kashitani, Thai Duong Nguyen, Kazuhiro Kusunose, Masato TAguchi, and Yoshihiro Takita: Aerodynamic Characteristics of Busemann Biplane by Wake Measurements in Low-Speed Wind Tunnel .......... 
Shun Watanabe, Shigeru SunadA, and Kohei Yamaguchi: Evaluation of Two-Hinged Wings....

Po-Hsun CHEN and Kojiro SuZUKI: CFD Study on Penetration of Sonic Boom Applying a Wavy-Water Model ........

Fengna CHENG, Jingzhou ZHANG, Jingyang ZHANG, and Yuyan ZHANG: Effect of Cutbacks on Tip Leakage Flow and

Film-Cooling Effectiveness of a Turbine Blade Tip under Relative Moving Condition...............
Hiroka INOUE and Shuichi ADACHI: Spatio-Temporal Path Planning for Lunar Polar Exploration with Robustness against Schedule Delay.

Yuta Ozawa, Taku Nonomura, Yuji SAITo, and Keisuke ASAI: Aeroacoustic Fields of Supersonic Twin Jets at the Ideally Expanded Condition.

Potsawat Boonjaipetch, Koji Shimoyama, and Shigeru Obayashi: Parametric Study on Waverider Configurations at Low-supersonic Speed for Low-boom Supersonic Transport ....

Yuto Iтон and Atsushi SAтон: Modeling and Numerical Investigation of Aerodynamic Characteristics of a Propeller Circling on a Whirling Arm.

Masaharu Matsumoto: Application of Deep Galerkin Method to Solve Compressible Navier-Stokes Equations ......

\section{RESEARCH NOTES}

Masatoshi Chono, Naoji Yamamoto, Ryudo TsukizaKi, Takato Morishita, Kenichi Kubota, Shinatra Cho, Kiyoshi KINEFUCHI, and Toru TAKAHASHI: Performance of a Miniature Hall Thruster and an In-house PPU

Makoto Matsui, Ryuji Kobayashi, Takashi OKamoto, Kazuhiko YamadA, and Hideyuki Tanno: Temperature Measurement of HEK-X Expansion Tube Flow by Laser Absorption Spectroscopy

Naoki Kanda, Kumi NAKAI, Yuji SAITo, Taku NonOmuRA, and Keisuke AsAI: Feasibility Study on Real-time Observation of Flow Velocity Field using Sparse Processing Particle Image Velocimetry

Donghoon KIM: Efficient Navigation for Unmanned Agents in Sparse Wireless Sensor Networks

Jumpei Kinoshita, Ryo IKedA, Misaki AdAChI, Ryo ShIRAKI, Taichi MoritA, Naoji YAMAmoto, Masakatsu NAKANO, Yasushi OHKAwA, and Ikkoh FunAKI: Position and Attitude Tolerances of Carbon Nanotube Field Emission Cathode as a Neutralizer in an Ion Engine System ..................................

Terukazu Tateno and Shigeru Sunada: Added Masses of an Elliptical Cylinder with Unsteady Motion or in Unsteady Flow 